\title{
Bimodal pore size behavior of the Shajara Formation Reservoirs of the Permo-Carboniferous Unayzah Group, Saudi Arabia
}

\author{
K. E. Al-Khidir • A. A. Al-Quraishi • \\ A. A. Al-Laboun $\cdot$ M. S. Benzagouta
}

Received: 29 September 2010/ Accepted: 21 March 2011/Published online: 5 April 2011

(C) The Author(s) 2011. This article is published with open access at Springerlink.com

\begin{abstract}
The sandstones of the Permo-Carboniferous Shajara Formation form the main part of the Unayzah Reservoir in the Greater Arabian Basin. It is divided into three reservoirs, namely from base to top Lower, Middle, and Upper Shajara reservoirs. Mercury intrusion technique was carried out on representative sandstone samples collected from the type section and the three reservoirs are generally characterized as heterogeneous megaporous reservoirs. The best reservoir quality is assigned to the lower sand unit of the Lower Shajara followed by the Middle Shajara Reservoir. One sample collected from the upper part of the Lower Shajara was described as low quality due to its fine grain characteristic and its proximity to the unconformity surface. Reservoir quality is controlled to a large extent by the depositional facies and specifically by rock texture illustrated by petrophysical description. The quality of the three reservoirs of the Shajara Formation, increases with the increase of grain size and grain sorting.
\end{abstract}

Keywords Shajara Reservoirs - Shajara Formation · Unayzah Group · Pore size distribution

K. E. Al-Khidir $(\bowtie) \cdot$ M. S. Benzagouta

Department of Petroleum and Natural Gas Engineering,

King Saud University, Riyadh, Saudi Arabia

e-mail: kalkhidir@ksu.edu.sa

\section{A. A. Al-Quraishi}

Oil and Gas Research Institute, King Abdulaziz City for Science and Technology, Riyadh, Saudi Arabia

A. A. Al-Laboun

Department of Geology, King Saud University,

Riyadh, Saudi Arabia

\section{Introduction}

The Permo-Carboniferous Unayzah Reservoirs are oil and gas bearing in more than 30 oil and gas fields in Saudi Arabia. These reservoirs are partially represented in outcrops by the Shajara, Safra, and Shiqqah sandstones of the Unayzah Group. These formations are exposed as a thin belt below the Khuff carbonates in central Arabia.

Fossil plants of the late Carboniferous-early Permian age were first reported at the town of Unayzah by ElKhayal et al. (1980). Later, the term Unazyah Formation was informally introduced by Al-Laboun (1982) as siliciclastics and minor carbonate section at the base of the Khuff Formation. This definition was adopted by Aramco Stratigraphic Committee (1983) and formally defined by Al-Laboun (1987)in the American Association of Petroleum Geologist (AAPG). The Unayzah Formation was then correlated with its equivalent units in different parts of the Greater Arabian basin (Al-Laboun 1988) and its type locality was established within Unayzah town with a reference section assigned at Wadi Ash-Shajara at the Qusayba depression, Al-Qasim region (Fig. 1).

The subsurface informal reference section (Hawtah-1) of the Unayzah Formation was studied by Ferguson and Chambers (1991). The section consists of two sandstone intervals separated by a coarsening upward siltstone unit. Similarly, McGillivray and Husseini (1992) divided the Unayzah Formation in the Hawtah-Hazmiyah fields into two informal sequences identified as Unayzah $\mathrm{A}$ and Unayzah B members. The two members are separated by a red-brown siltstone or fine-grained silty sandstone. Senalp and Al-Dauji (1995) studied the stratigraphy and sedimentation of the Unayzah Reservoir in central Arabia. They redefined the Unayzah Formation at its type locality by introducing the term "basal Khuff clastics" (Ash-Shiqqah 


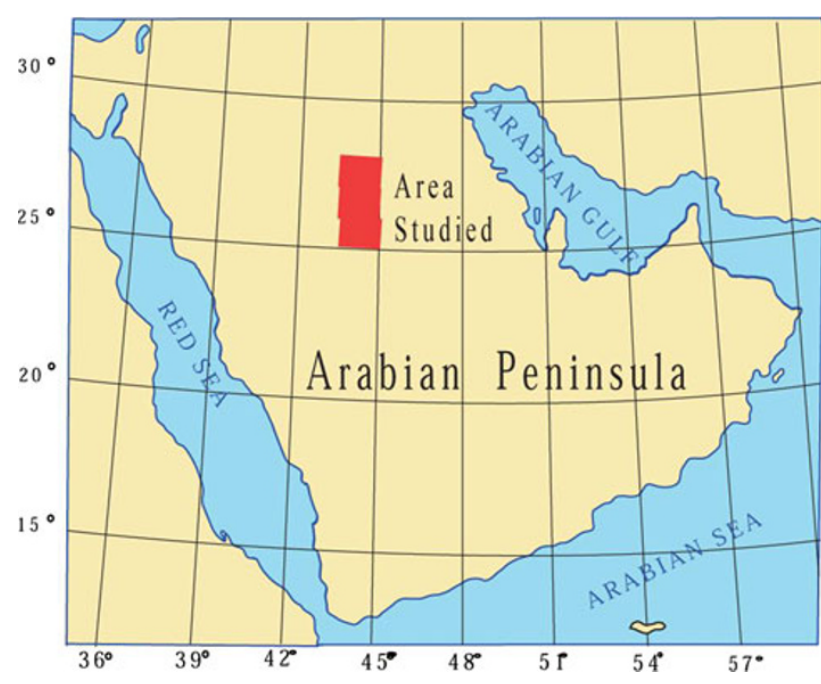

Fig. 1 Location map of the studied area

member) of the Khuff Formation to be the upper contact of the Unayzah Formation.

Evans et al. (1997) studied the stratigraphic trap in the Permian Unayzah Formation, in Usaylah-1, central Arabia, and they reported that the trap is an up dip pinch out. An oil column $31 \mathrm{ft}$ thick is encountered in the eolian sandstone facies of the upper part of the Unayzah Formation. Later, Wender et al. (1998) divided the Early Permian Unayzah Formation into three units, the Unayzah-A Reservoir, Unayzah Siltstone Member, and Unayzah-B Reservoir. Melvin and Spraque (2006) studied origin and stratigraphic architecture of glaciogenic sediments in Permian-Carboniferous lower Unayzah sandstones in eastern central Saudi Arabia. They subdivided the lower Unayzah sandstones into three members, from base to top are: Unayzah $\mathrm{C}$ Member, Unayzah B Member, and an un-named middle Unayzah member.

Reservoir characteristics of the Permo-Carboniferous Unayzah Formation, at Wadi Shajara was thoroughly investigated through field and petrophysical examinations. An exposed clastic sequence consisting of three sandstone intervals separated by two mudstone units were observed (Fig. 2). The clastic sequence is bounded from top and bottom, by two regional unconformities, namely sub-Khuff and sub-Unayzah unconformity, respectively. Based on Saudi Stratigraphic Code (1983), a group is defined as a lithostratigraphic unit bounded by two regional unconformities. Therefore, we propose raising the Permo-Carboniferous Unayzah Formation to a group status and identify a new formation named Shajara Formation (Al-Khidir 2007). The term Unayzah Formation was restricted to the upper unit of the group which is best represented in its original type locality in Unayzah town, while the term Shajara Formation was assigned to the Lower unit which is best represented at Wadi Ash-Shajara (Laboun 2010). Depending on sub-Unayzah unconformity, sub-middle Shajara local unconformity, the lower mudstone interval, and subKhuff unconformity (Fig. 2), the Shajara Formation was divided into three members, from base to top: the Lower Shajara, the Middle Shajara, and the Upper Shajara (Al-Khidir 2007).

The Shajara Reservoirs of the Shajara Formation is oil and gas bearing in many fields in Saudi Arabia. In addition, it is the principal Paleozoic clastic reservoir. To our knowledge no petrophysical examination was conducted on the surface samples of the Shajara Formation. The aim of this work is to categorize the Shajara reservoirs by characterizing the pore geometry and the pore aperture sizes of the sandstones. This is done by integrating capillary pressure obtained by the mercury injection porosimetry technique, petrofacies determination and lithofacies description of outcrop samples collected.

\section{Experimental work}

The most obvious and straightforward measurements of pore size are with geometric analysis of images of individual pores. This can be done using various types of microscopy on thin sections or other flat soil surfaces, or tomography. Image-based techniques can be prohibitively tedious because enough pores must be analyzed to give an adequate statistical representation. Therefore, the determination of pore geometry and pore aperture size using mercury injection technique is believed to be more helpful in categorizing rocks by pore types (i.e. nanno, micro, meso, macro or mega). Autopore III 9420 mercury intrusion unit was used to determine the capillary pressure, porosity, pore throat accessibility, and pore level heterogeneity of the three reservoirs comprising the Shajara Formation. This was conducted on nine outcrop sandstone samples selected among 13 samples from the type section. All samples except for one (SJ3) are friable sand and their locations are presented in stratigraphic column illustrated in Fig. 2.

Samples' permeability $(k)$ was calculated utilizing Purcell's equation (1948) stated as:

$K=14,260 \times \lambda \times \phi \times \int_{s=0}^{s=1} \frac{\delta S_{\mathrm{Hg}}}{P_{\mathrm{c}}}$

where, $\lambda$ is a lithology factor (equal to 0.216 ), $\delta S_{\mathrm{Hg}}$ is incremental mercury saturation and $P_{\mathrm{c}}$ is the capillary pressure measured in psi.

The pore aperture size is calculated utilizing Washburn equation expressed as: 
Fig. 2 Stratigraphic column of the type section of the Permocarboniferous Shajara

Formation of the Unayzah Group, Wadi Shajara, Qusayba area, al Qassim district, Saudi Arabia, N $26^{\circ} 5217.4$, E $43^{\circ} 36$ 18

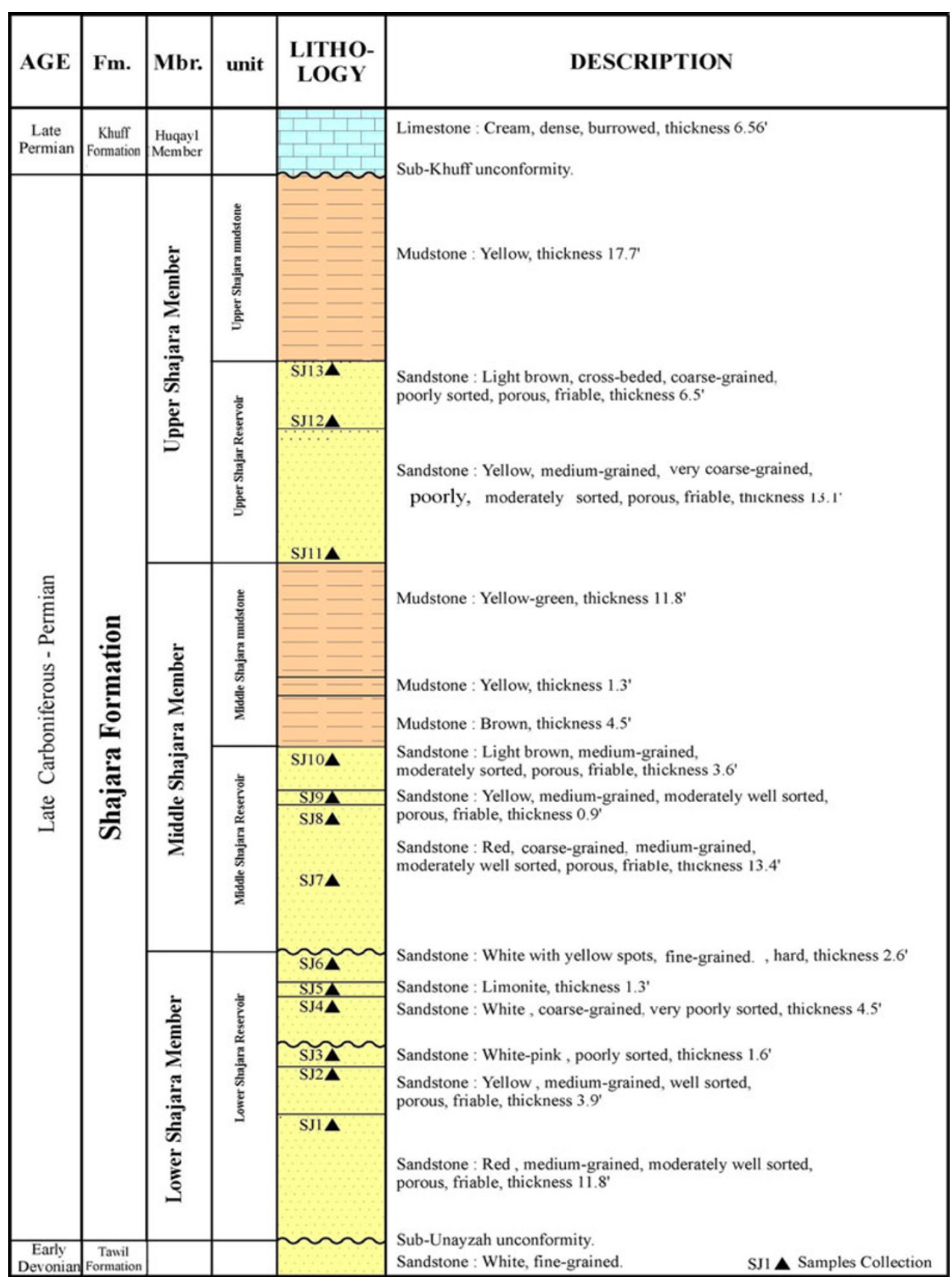

$r=\frac{2 \times \sigma \times \cos \theta}{P_{\mathrm{c}}}$

where, $r$ is the pore radius in micron, $\sigma$ is the surface tension of mercury in Dynes/cm, $\theta$ is the contact angle of mercury in air and $P_{\mathrm{c}}$ is the capillary pressure in Dynes $/ \mathrm{cm}^{2}$.

To reveal the heterogeneity of the investigated reservoirs, the pore aperture distribution (PSD) was plotted as a function of pore radius. The PSD function is defined as the rate of change of mercury intrusion volume with respect to the difference of pore radius logarithm relative to the maximum value of that term. To confirm the findings of the
PSD plots, the cumulative percent of mercury saturation was plotted with respect to log pore radius.

On average, the pore throats entered by a non-wetting fluid (mercury) at $35 \%$ saturation $\left(R_{35}\right)$ or less during a capillary analysis, represent the pores that dominate fluid flow in a reservoir samples (Kolodzie 1980). The pore throat corresponding to a mercury saturation of $35 \%$ was evaluated using Winland equation expressed as:

$\log R_{35}=0.732+0.588 \times \log k-0.864 \times \log \phi$

Pittman (2001) reported that, pore throat radius corresponding to the apex has the potential for delineating 
stratigraphic traps in the same manner as the pore aperture corresponding to 35 th percentile of a cumulative mercury saturation curve, which was developed by Winland. Therefore, the pore aperture size corresponding to the apex $\left(R_{\text {apex }}\right)$ was determined from Pittman equation stated as follows:

$\log R_{\text {apex }}=-0.117+0.475 \times \log k-0.099 \times \log \phi$

\section{Results and discussion}

In order to determine the behavior of the pore geometry of Shajara Reservoirs, samples capillary pressures were measured and the measurements were used to determine the pore size distribution. Figure 3 is the pore size distribution of sample SJ1 representing the Lower Shajara Reservoir. This sample is characterized as red in color, medium grain size and moderately well sorted. The figure indicates a bimodal pore size distribution of two distinct pore sizes, minor macro pores of sizes less than $10 \mu \mathrm{m}$ and major mega pores with size greater than $10 \mu \mathrm{m}$ according to Libny et al. classification (2001). Within the mega pores there exist a variation in pore size. The sample is characterized with maximum pore radius of $173.9 \mu \mathrm{m}$, and a minimum radius of $0.01 \mu \mathrm{m}$, and an average pore size of $41.6 \mu \mathrm{m}$. Variation in pore size distribution demonstrates the possibility of anisotropy. This anisotropy is well defined in Fig. 4 where three distinct tracks have been obtained. The pore radii of the first track ranges from 60.2 to $173.9 \mu \mathrm{m}$. The second represents pore radii varying from 0.1 to $60.2 \mu \mathrm{m}$, whereas the third track is characterized by very low pore radii ranging in size from 0.1 to $0.01 \mu \mathrm{m}$.

Sample SJ2 is the second sample representing the Lower Shajara Reservoir. It is described as medium-grained, well sorted sandstone. Figure 5 is the pore size distribution of the sample indicating a bimodal pore size distribution with

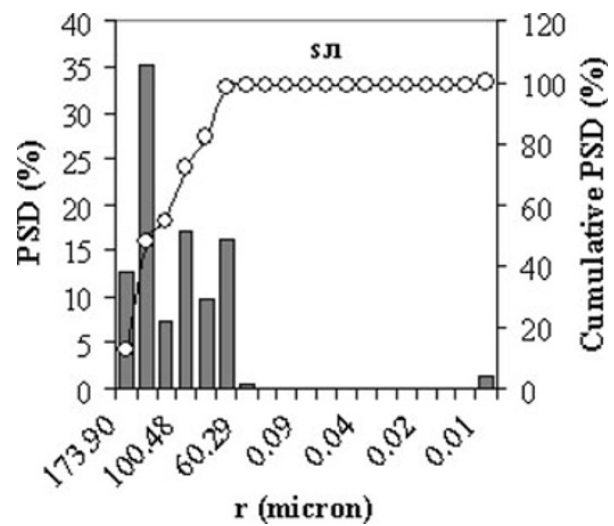

Fig. 3 Incremental and cumulative PSD versus pore radius of sample SJ1 from the Lower Shajara Reservoir

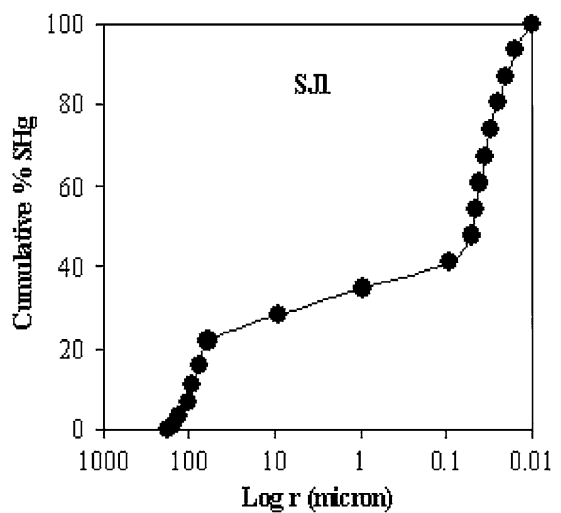

Fig. 4 Cumulative $\% S_{\mathrm{Hg}}$ versus pore radius of sample SJ1 from the Lower Shajara Reservoir

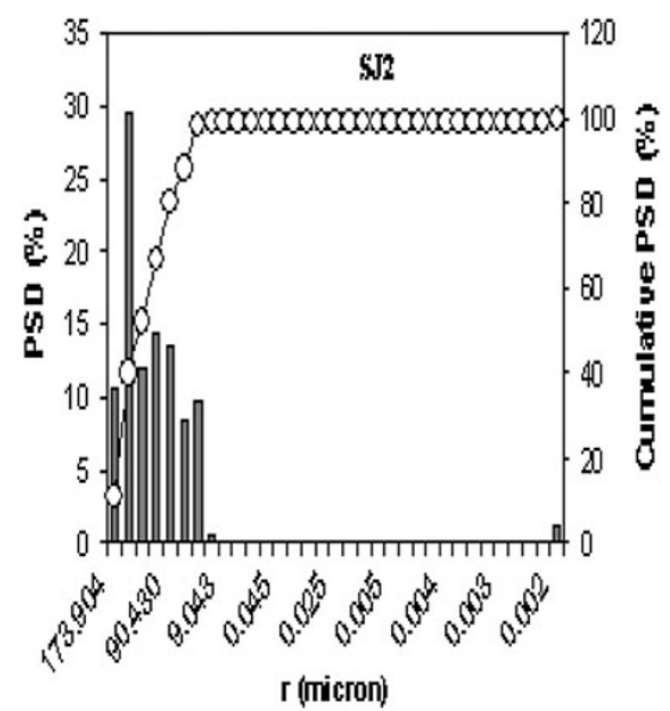

Fig. 5 Incremental and cumulative PSD versus pore radius of sample SJ2 from the Lower Shajara Reservoir

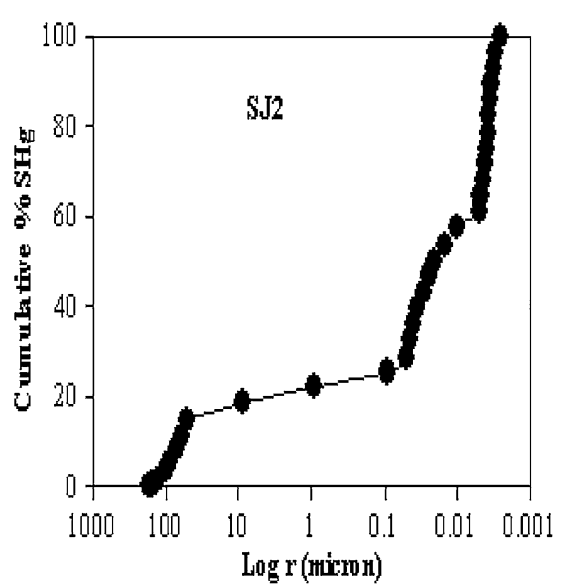

Fig. 6 Cumulative $\% S_{\mathrm{Hg}}$ versus pore radius of sample SJ2 from the Lower Shajara Reservoir 
Table 1 Petrophysical properties of samples tested

\begin{tabular}{|c|c|c|c|c|c|c|c|c|}
\hline Petrophysical facies & $\Phi(\%)$ & $K(\mathrm{mD})$ & $R_{35}(\mu \mathrm{m})$ & $R_{\text {apex }}(\mu \mathrm{m})$ & $h$ (feet) & $\Phi$ avg. (\%) & $K$ avg. $(\mathrm{mD})$ & Reservoir \\
\hline $\mathrm{Sj}-1$ & 29.2 & 1,680 & 23 & 18.6 & 11.8 & 31.1 & 1,592 & Lowe Shajara Reservoir \\
\hline $\mathrm{Sj}-2$ & 35.5 & 1,955 & 21.3 & 19.6 & 3.9 & & & \\
\hline $\mathrm{Sj}-3$ & 34.2 & 56 & 2.7 & 3.6 & 1.6 & & & \\
\hline $\mathrm{Sj}-7$ & 35.1 & 1,472 & 18.2 & 17.2 & 13.4 & 33.4 & 1,407 & Middle Shajara Reservoir \\
\hline $\mathrm{Sj}-8$ & 31.9 & 1,344 & 18.7 & 16.8 & & & & \\
\hline $\mathrm{Sj}-9$ & 31.5 & 1,395 & 19.3 & 16.9 & 0.9 & & & \\
\hline $\mathrm{Sj}-11$ & 36.2 & 1,197 & 15.7 & 15.5 & 13.1 & 29.9 & 1,204 & Upper Shajara Reservoir \\
\hline $\mathrm{Sj}-12$ & 28.2 & 1,440 & 21.7 & 17.4 & & & & \\
\hline $\mathrm{Sj}-13$ & 25.4 & 973 & 18.8 & 14.6 & 6.5 & & & \\
\hline
\end{tabular}

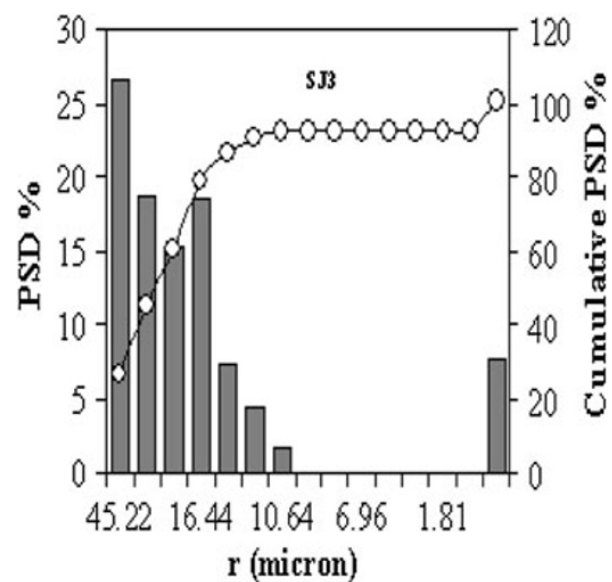

Fig. 7 Incremental and cumulative PSD versus pore radius of sample SJ3 from the Lower Shajara Reservoir

a maximum pore radius of $173.9 \mu \mathrm{m}$, and an average pore size of $25.4 \mu \mathrm{m}$. Again two distinct pore sizes exist with majority of the sizes classified as megapores. Figure 6 confirms the heterogeneity of the sample as presented by multiple tracks with distinctive pore radius ranges.

Sample SJ3 of the Lower Shajara Reservoir is characterized with finer grain size when compared to samples SJ1 and SJ2. Such grain size variability as well as compaction noticed through grains visual inspection is believed to be due to the sample proximity to the unconformity surface. This is reflected in a drastic drop in permeability of sample $\mathrm{SJ} 3$ as stated in Table 1. The sample is also identified with bimodal pore size distribution with skewness towards finer pore size as indicated in Fig. 7. The sample is characterized with narrower range of pore radii variation and smaller pore sizes compared to that of samples SJ1 and SJ2. Again, Fig. 8 exhibits two tracks of pore radii ranging in size from 10 to $45 \mu \mathrm{m}$, and from 1 to $10 \mu \mathrm{m}$.

Grain size assessment, pore size distributions and calculated petrophysical properties of porosity and permeability of samples SJ1, SJ2 and SJ3 can help assessing the Lower Shajara Reservoir. This can be confirmed by the Winland

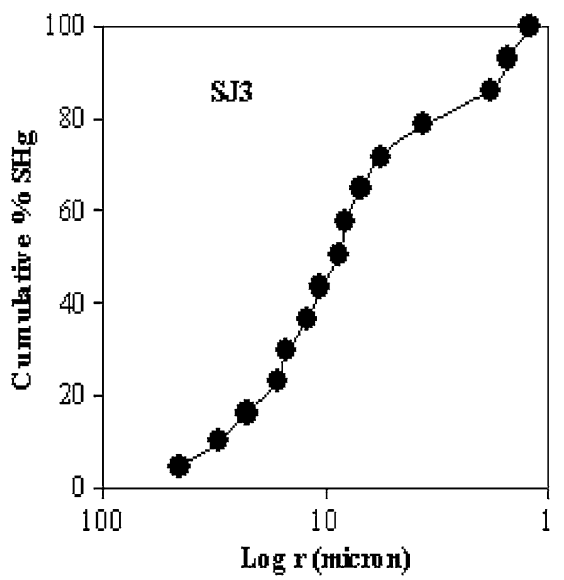

Fig. 8 Cumulative $\% S_{\mathrm{Hg}}$ versus pore radius of sample SJ3 from the Lower Shajara Reservoir

$R_{35}$ and Pittman $R_{\text {apex }}$ (Table 1). Based on the grain size description and the obtained porosity and particularly permeability, it can likely be stated that the average pore size decreases as the grain size gets finer and as a consequence flow capacity declines. This is observed as we proceed upward in the reservoir. Based on that and the reservoir classification utilizing the Winland $R_{35}$, the lower part of the reservoir can be classified as megaporous (pore radius greater than $10 \mu \mathrm{m}$ ), whereas the upper portion of the reservoir represented by sample SJ3 is classified as macroporous (pore radius between 2 and $10 \mu \mathrm{m}$ ) with lower flow capacity as stated by the low permeability value (Table 2 ).

Middle Shajara Reservoir were characterized using samples SJ7, SJ8 and SJ9. Sample SJ7 is described as coarse-grained, moderately well sorted sandstone. This sample is characterized by bimodal pore size distribution as shown in Fig. 9 with pore radii ranging from 1.2 to $180.8 \mu \mathrm{m}$ with an average value of $46.15 \mu \mathrm{m}$. The sample heterogeneity is revealed in Fig. 10, where two tracks of pore radii exists. The first represents a pore radii ranging from 10 to $180.8 \mu \mathrm{m}$, whereas the second represents pore radii that vary from 1.2 to $10 \mu \mathrm{m}$. 
Table 2 Lithofacies description of samples tested

\begin{tabular}{lllll}
\hline Facies no. & Color & Grain size & Sorting & Hardness \\
\hline SJ-1 & Red & Medium-grained & Moderately well sorted & Friable \\
SJ-2 & Yellow & Medium-grained & Well sorted & Friable \\
SJ-3 & White-pink & Fine-grained & Poorly sorted & Hard \\
SJ-7 & Red & Coarse-grained & Moderately well sorted & Friable \\
SJ-8 & Red & Medium-grained & Moderately well sorted & Friable \\
SJ-9 & Yellow & Medium-grained & Moderately well sorted & Friable \\
Sj-11 & Yellow & Medium-grained & Poorly sorted & Friable \\
SJ-12 & Yellow & Very coarse-grained & Moderately sorted & Friable \\
SJ-13 & Light brown & Coarse-grained & Moderately sorted & Friable \\
\hline
\end{tabular}
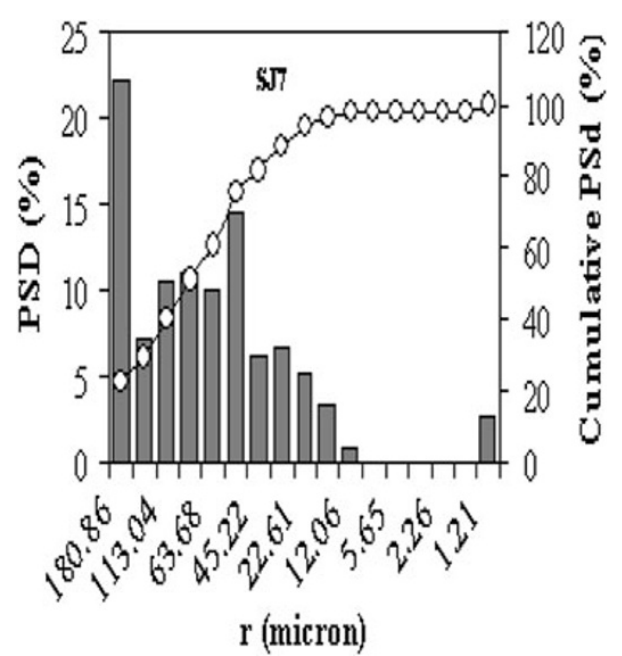

Fig. 9 Incremental and cumulative PSD versus pore radius of sample SJ7 from the Lower Shajara Reservoir

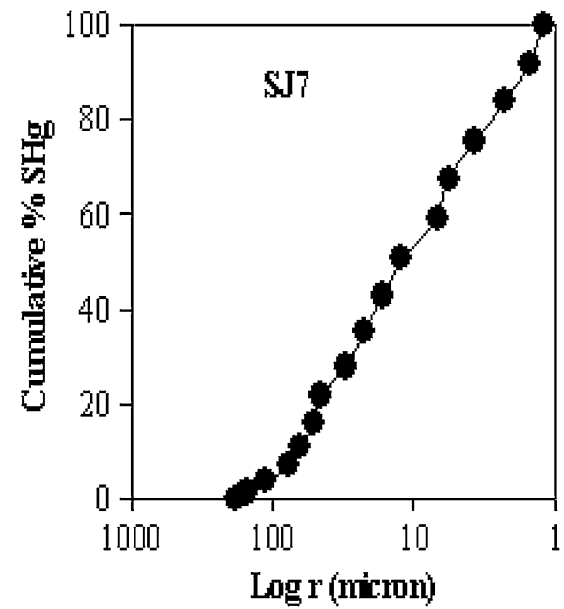

Fig. 10 Cumulative $\% S_{\mathrm{Hg}}$ versus pore radius of sample $\mathrm{SJ} 7$ from the Lower Shajara Reservoir

Sample SJ8 is also identified as medium-grained, moderately well sorted sandstone. This sample is characterized with bimodal pore size distribution as shown in Fig. 11

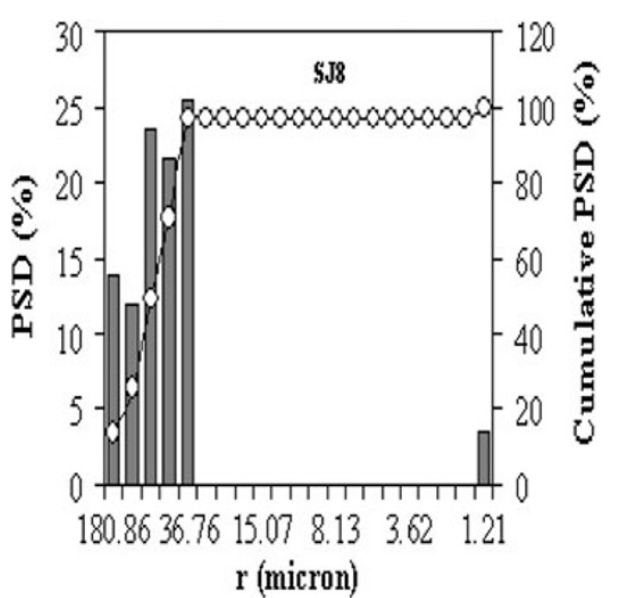

Fig. 11 Incremental and cumulative PSD versus pore radius of sample SJ8 from the Lower Shajara Reservoir

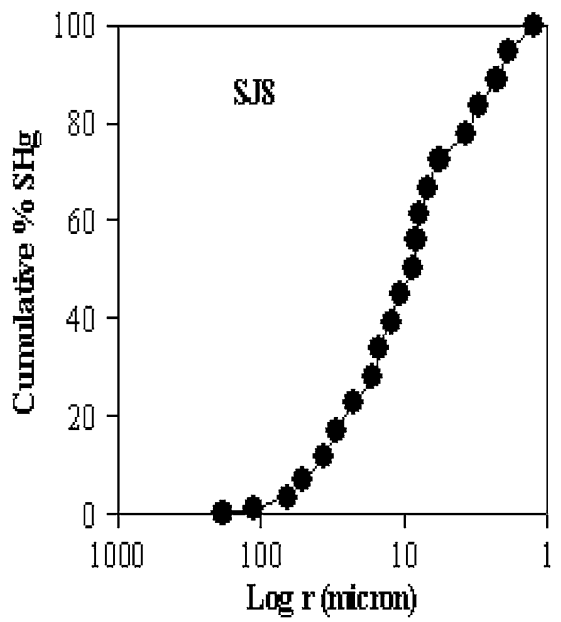

Fig. 12 Cumulative $\% S_{\mathrm{Hg}}$ versus pore radius of sample SJ8 from the Lower Shajara Reservoir

with an average pore radius of $28.65 \mu \mathrm{m}$ indicating smaller average pore size than that of sample SJ7. The heterogeneity of this sample is affirmed in Fig. 12 which displays 
two tracks of pore radii. The first is for a pore radii that range in size from 37 to $180.8 \mu \mathrm{m}$, whereas the second is characterized by pore radii varying in size from 1 to $10 \mu \mathrm{m}$.

Similar to the above two samples of the Middle Shajara Reservoir, sample SJ9 is described as medium-grained, moderately well sorted sandstone. This sample is characterized with bimodal pore size distribution as indicated in Fig. 13 with an average pore radius of $73.9 \mu \mathrm{m}$ indicating the largest mean pore size for this section of the reservoir. Further verification of heterogeneity of this sample is indicated in Fig. 14 which indicates two tracks of pore radii, ranging in size from 10 to $164.4 \mu \mathrm{m}$ and 1 to $10 \mu \mathrm{m}$. Based on the outcomes obtained and the Winland $R_{35}$ and Pittman $R_{\text {apex }}$ (Table 1), the whole Middle Shajara Reservoir is classified as megaporous reservoir with good flow capacity.

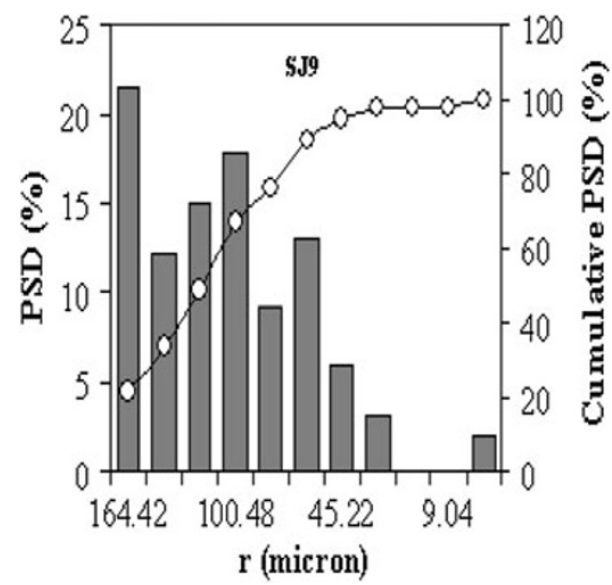

Fig. 13 Incremental and cumulative PSD versus pore radius of sample SJ9 from the Lower Shajara Reservoir

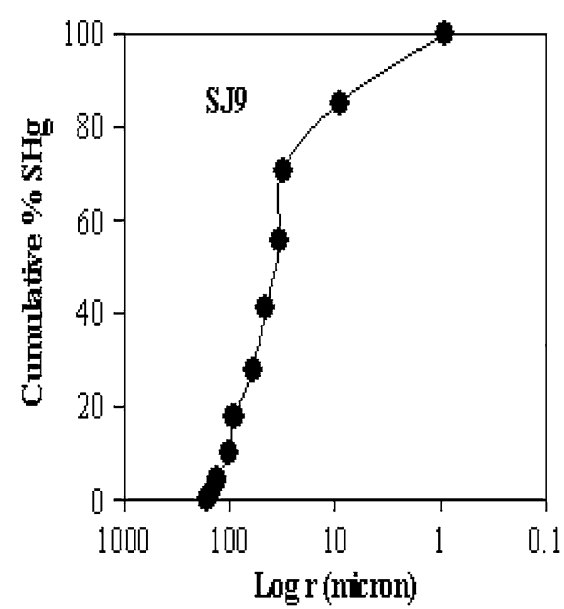

Fig. 14 Cumulative $\% S_{\mathrm{Hg}}$ versus pore radius of sample SJ9 from the Lower Shajara Reservoir
The Upper Shajara Reservoir is also represented by three samples, namely from base to top SJ11, SJ12, and SJ13. Sample SJ11 is identified as medium-grained, poorly sorted sandstone. This sample is characterized with bimodal pore size distribution as illustrated in Fig. 15. This variation in pore size distribution is proved in Fig. 16 where three tracks of pore distribution are observed. The first track is for pore radii varying in size from 30 to $173.9 \mu \mathrm{m}$. The second track represents distribution of pore radii ranging in size from 0.1 to $30 \mu \mathrm{m}$. The third track represents a very small pore radii range of $0.01-0.1 \mu \mathrm{m}$. This sample has a mean pore radius of $42.9 \mu \mathrm{m}$.

Sample SJ12 is identified as very coarse-grained, moderately sorted sandstone. This sample is also characterized with bimodal pore size distribution as illustrated in Fig. 17. This sample possesses an average pore radius of $67.7 \mu \mathrm{m}$. The pore heterogeneity is verified in Fig. 18 where two

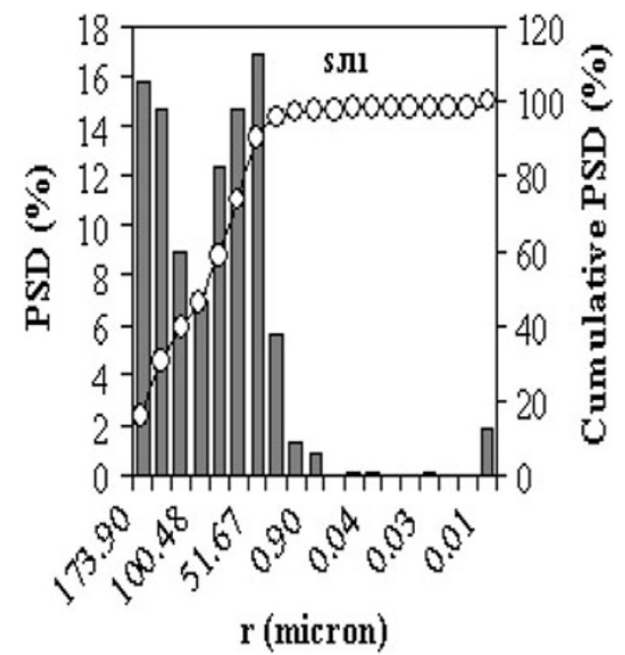

Fig. 15 Incremental and cumulative PSD versus pore radius of sample SJ11 from the Lower Shajara Reservoir

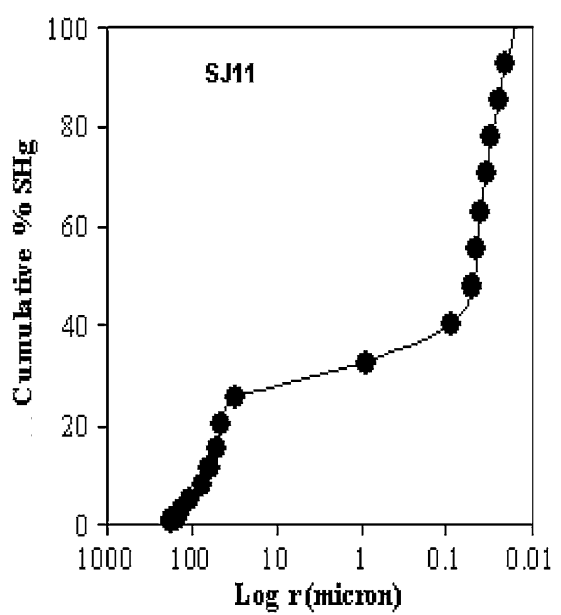

Fig. 16 Cumulative $\% S_{\mathrm{Hg}}$ versus pore radius of sample SJ11 from the Lower Shajara Reservoir 


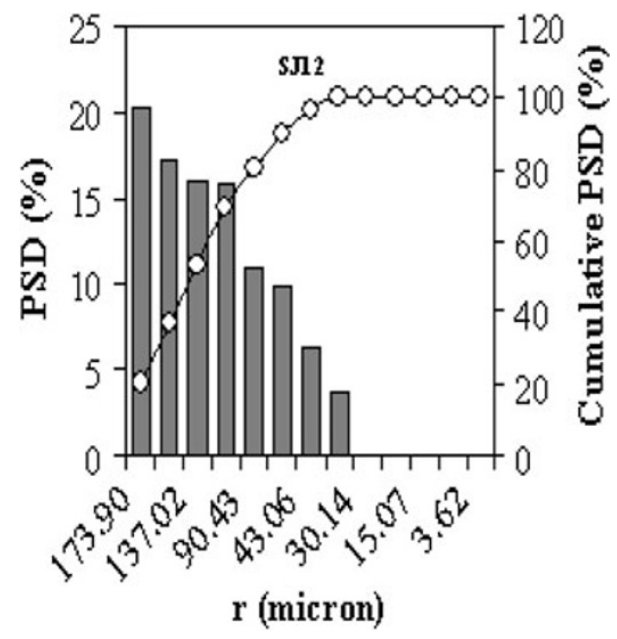

Fig. 17 Incremental and cumulative PSD versus pore radius of sample SJ12 from the Lower Shajara Reservoir

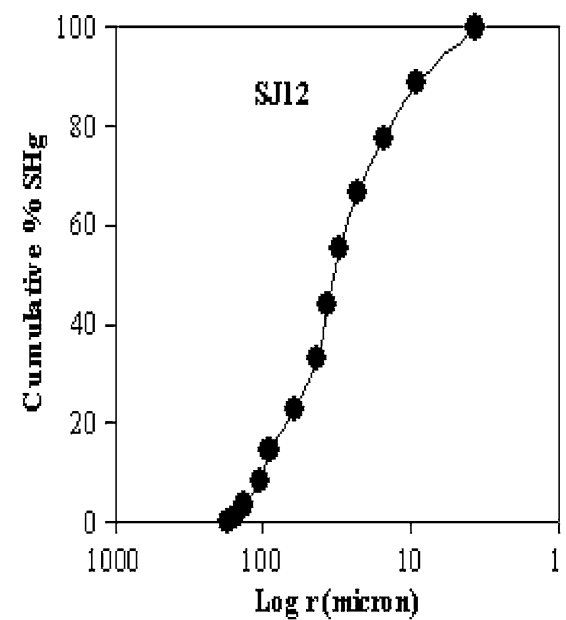

Fig. 18 Incremental and cumulative $\% S_{\mathrm{Hg}}$ versus pore radius of sample SJ12 from the Lower Shajara Reservoir

tracks of pore size distribution exist. The first having pore radii ranging in size from 36 to $173.9 \mu \mathrm{m}$, whereas the second ranges from 3.6 to $36 \mu \mathrm{m}$.

Sample SJ13 represents the upper section of the reservoir. It is described as coarse-grained, moderately sorted sandstone. Again it is characterized with bimodal pore size distribution as illustrated in Fig. 19 with an average pore radius of $25.2 \mu \mathrm{m}$. This sample is also considered heterogeneous as indicated in Fig. 20 where three distinct tracks of pore radii are observed. Reservoir classification of the Upper Shajara can be considered as megaporous.

In an overall view, and based on the relationship of $R_{35}$ and $R_{\text {apex }}$ presented in Fig. 21, the reservoir quality of the Shajara Formation increases with the increase in mean pore radius corresponding to the apex and to that corresponding to $35 \%$ mercury saturation. Good correlation was obtained

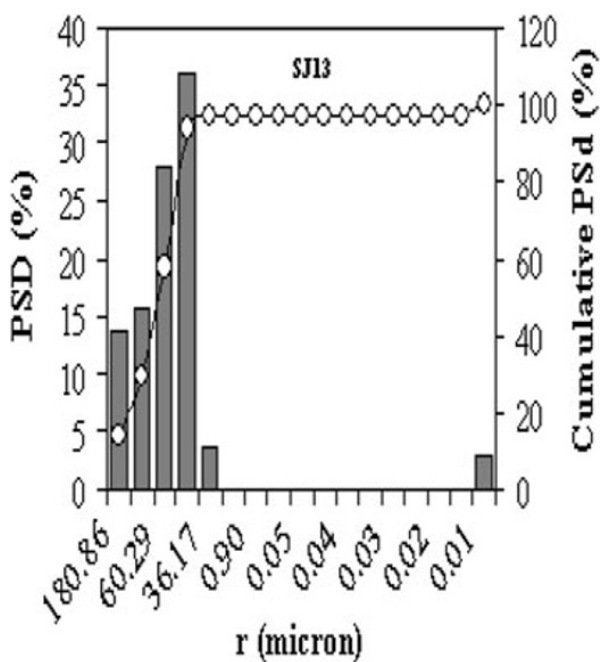

Fig. 19 Incremental and cumulative PSD versus pore radius of sample SJ13 from the Lower Shajara Reservoir

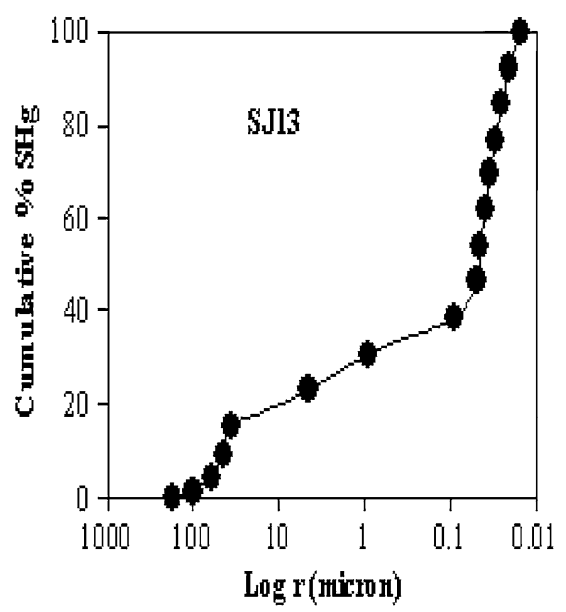

Fig. 20 Cumulative $\% S_{\mathrm{Hg}}$ versus pore radius of sample $\mathrm{SJ} 13$ from the Lower Shajara Reservoir

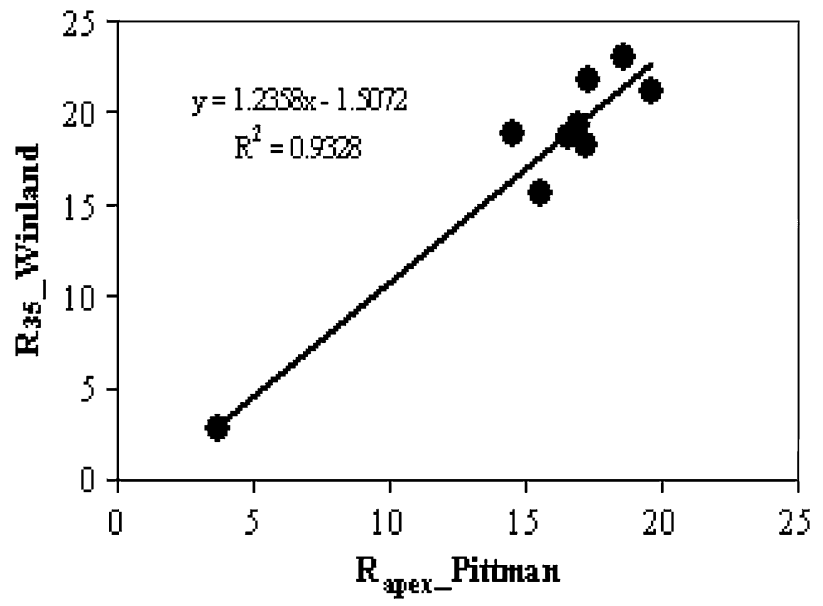

Fig. 21 Winland $R_{35}$ versus Pittman $R_{\text {apex }}$ 
for the $R_{35}$ versus $R_{\text {apex }}$ and all samples mean pore sizes are grouped at megaporous category except for sample SJ3 which falls on macroporous category confirming the previously discussed pore size identification. In conclusion, grain and pore size variability are the controlling factor on the Shajara reservoir quality assessment.

\section{Conclusions}

- The three reservoirs of the Shajara Formation are characterized as heterogeneous reservoirs.

- In general, the three Shajara Reservoirs are classified as megaporous, with average pore size of 22,49 and $45 \mu \mathrm{m}$ for the Lower, Middle, and Upper Shajara Reservoirs, respectively. However, the best reservoir quality is assigned to the lower sand unit of the Lower Shajara followed by the Middle Shajara Reservoir.

- Pore radius corresponding to the apex and that corresponding to the $35 \%$ mercury saturation confirms the reservoir classification indicating megaporous reservoirs except for SJ3 of the Lower Shajara which has low quality due to its fine grain characteristic and its proximity to the unconformity surface.

- An excellent correlation factor of 0.93 was obtained when Winland $R_{35}$ was plotted versus Pittman $R_{\text {apex }}$.

- Reservoir quality is controlled to a large extent by the depositional facies and specifically by rock texture illustrated by petrophysical description. The quality of the Shajara Formation reservoirs increases with the increase in grain size and grain sorting.

Open Access This article is distributed under the terms of the Creative Commons Attribution Noncommercial License which permits any noncommercial use, distribution, and reproduction in any medium, provided the original author(s) and source are credited.

\section{References}

Al-Khidir KE (2007) Reservoir characteristics of the Unayzah formation. MSc thesis, King Saud University, Riyadh, Kingdom of Saudi Arabia
Al-Laboun AA (1982) Subsurface stratigraphy of the Pre-Khuff formations in central and northwestern Arabia. $\mathrm{PhD}$ thesis, King Abdulaziz University, Jeddah, Kingdom of Saudi Arabia

Al-Laboun AA (1987) Unayzah Formation: a new Permo-Carboniferous unit in Saudi Arabia. Am Assoc Petrol Geol Bull 71(1):29-38

Al-Laboun AA (1988) The distribution of the Carboniferous-Permian Siliciclastics in the Greater Arabian Basin. Geol Soc Am Bull 100(3):362-373

El-Khayal AA, Chaloner WG, Hill CR (1980) Paleozoic plants from Saudi Arabia. Nature 285:33-34

Evans DS, Bahabri BH, Al-Qtaibi AM (1997) Stratigraphic trap in the Permian Unayzah Formation, Central Saudi Arabia. GeoArabia 2:259-278

Ferguson GS, Chambers TM (1991) Subsurface stratigraphy, depositional history, and reservoir development of the early-to-late Permian Unayzah Formation in Central Saudi Arabia. In: Paper SPE 21394 presented at the middle east oil show held in Bahrain, Nov. 16-19

Kolodzie SJ (1980) Analysis of pore throat size and use of the Waxman-Smits equation to determine OOIP in spindle field. In: Paper SPE 9382, 55th annual fall technical conference, Colorado

Libny L, Roberto R, Quaglia A, Porras JC, and Lazarde H (2001) Bimodal behavior of mercury injection capillary pressure curve and its relationship to pore geometry, rock quality and production performance in a laminated and heterogeneous reservoir. In: SPE 69457 presented at Latin America and Caribbean Petroleum Engineering Conference, Argentina, March 25-28

McGillivray JG, Husseini MI (1992) The Paleozoic petroleum geology of central Arabia. Am Assoc Petrol Geol Bull 76(10): 1473-1490

Melvin J, Sprague A (2006) Origin and stratigraphic architecture of galciogenic sediments in Permian-Carboniferous Lower Unayzah Sandstones, Eastern Central Saudi Arabia. GeoArabia 11(4):105-152

Pittman ED (2001) Estimating pore throat size in sandstones from routine core analysis data

Purcell WR (1948) Capillary pressures-their measurement using mercury and the calculation of the permeability therefrom, AIME, T.P.2544

Senalp M, Al-Dauji A (1995) Stratigraphy and sedimentation of the Unayzah Reservoir, Central Saudi Arabia. In: Husseini MI (ed) The middle east petroleum geosciences, Geo 94, Gulf Petrolink, Bahrain, vol 2, pp 837-847

Wender LE, Bryant JW, Dicken MF, Neville AS, Al-Moqbel AM (1998) Paleozoic (Pre-Khuff) hydrocarbon geology of the Ghawar area, Eastern Saudi Arabia. GeoArabia 3(2):273-302 